\title{
MISCELLANEOUS.
}

\section{ON A FISH ALLIED TO LEPIDOSIREN ANNECTENS.}

Aт the sitting of the Berlin Academy on the 5 th of December 1844, Prof. Müller presented a communication from Dr. Peters, " On a fish from the Quellimane marshes provided with both lungs and gills, related to Lepidosiren annectens."

This animal, which resides during the dry season in a cavity formed in the earth and lined with leaves, resembles the Lepidosiren annectens so completely in many points of its external and internal organization, that Dr. Peters is inclined to regard these two animals as identical, and to consider the distinguishing characters of the latter as consequent on our still imperfect knowledge of it. The composition of the skull, the vertebral column, the arches furnished with and those not furnished with gills, the lungs, alimentary canal, the generative organs, the brain, heart, external form, scales, and the teeth are exactly as in the Lepidosiren annectens. The pectoral and ventral fins, the labial cartilages, the perforated nostrils, and the existence of external gill-filaments differ from what has been hitherto described in the latter.

The pectoral and ventral fins do not consist of merely a single articulated member or ray, but also of cartilaginous rays, which emanate from the inferior margin of the main limb or principal ray of the fin, and to which still finer cartilaginous filaments are attached. These rays are not extensions of the main limbs of the fin, but are attached to it ; the length of the rays diminishes towards the end of the main limb or principal ray of the fin until it becomes inappreciable; the extremities of the rays do not lie loosely upon the skin, but the whole fin is covered by a prolongation of the skin, which also covers the principal ray of the fin. In the pectoral fins, the beard of the fin is as long as its ray. In the ventral fins, one-third of the length of the ray is free at the base of the fin; this then commences very low and remains much lower than in the pectoral fins. In the latter the beard of the fin external to the ray is 3 lines broad in its widest part. This kind of formation of the fins, in which the rays arise laterally from a main ray, is quite peculiar, and we have no other example of it amongst fish except in the dorsal fin of Polypterus.

The nostrils are double, and the posterior lies on the palatal side of the upper lip, as in Lepidosiren paradoxa, the labial cartilage of which is similarly placed.

There are three gill-filaments above the thoracic fin behind the gillaperture ; they are not branched, and consequently appear like tentacles; they are placed closely together, one above the other. Two are of equal length, being 4 lines long; the third is the lowest, and is much shorter. They are not present in the young specimens only, but in all, even those which have attained the length of 2 feet.

These filaments, which are somewhat broad and pointed at the extremity, are composed at their fore-part of a continuation of the external skin of the animal ; the posterior part exhibits fine feathery ramifications of blood-vessels. In the middle line of the posterior 
part this surface is smooth; its lateral surfaces have a colourless, soft, velvety aspect, and with a lens, crowded, small, shaggy prolongations are perceptible, in which the arteries and veins of the gills ramify. These vessels are elongations of the vessels of the inner gills; we find them also at the posterior part of the gill-aperture, between the upper end of the gill-arches and the external gills beneath the skin covering the gill-aperture : they are five, three arteries and two veins. One of the arteries arises from the second aortic arch ; the two others are the continuation of the extremities of the gill-arteries of the first and middle of the three posterior and internal gills. The two other vessels, which return the blood from the external gills, terminate in the gill-veins of the first and second of the three internal and posterior gills, after they have separated from the superior extremity of their gill-arches. The most anterior gill, at the anterior margin of which the gill-cavity is situated, and is separated by a cleft from the most anterior of the two gill-arches which are unfurnished with gills, is a true respiratory gill, and thus represents the supernumerary respiratory gill of the cartilaginous fishes, not the pseudo-branchia of other fishes. It receives a branch of the gill-artery and gives off superiorly a gill-vein, which eorresponds to the carotis anterior. It is however remarkable that the artery of the most anterior gills, although it arises in the same manner as the other gill-arteries, yet before it enters the gill gives off a branch for the nutrition of the body, which is distributed to the inferior aspect of the most anterior part of the head, to the skin and muscles of this part; a fact which is unique in ichthyology, and can only be explained from the gillarteries of the heart conveying not only dark red but also partly bright red (arterial) blood, which is transmitted from the lungs to the heart. The auricle of the heart is single. The spleen of the Lepidosiren has hitherto been overlooked. It is large, and lies behind the stomach and commencement of the intestinal canal, beneath the peritoneal coat of the tractus intestinalis. It must be separated from the black pigment which forms a copious substratum beneath the peritoneal covering of the intestines. The lateral anus is not always situated on the same side, being in some on the right, in others on the left.

Should Lepidosiren annectens and the fish of Quellimane belong to different genera, which is not probable, Dr. Peters proposes Rhinocryptis amphibia for the name of the latter. A circumstance which is much in favour of their identity, and renders it probable that we are not perfectly acquainted with Lepidosiren annectens, is, that this has been lately observed by Jardine* also to have filaments on the pectoral fins; these were mistaken by Jardine for accessory fin-rays.

The next point to be determined is, whether the cartilaginous finrays found in the fish of Quellimane are present in Lepidosiren annectens. Then comes the question, whether these and the external branchial filaments are also present in Lepidosiren paradoxa. Upon this will depend whether the African fish, although identical in genus,

* Ann. of Nat. Hist. vol. vii. p. 24. 
is generically different from the American genus Lepidosiren, and whether the generic name Protopterus proposed by Owen for the Lepidosiren annectens should be restored or not.

\section{On the African Musk, Moschus aquaticus, Ogilby.}

Some time ago Mr. Ogilby, in the Proceedings of the Zoological Society for 1840, described an animal in the collection of the Earl of Derby under the name of Moschus aquaticus, which was very interesting as being an African species of a genus which had hitherto only been found in Asia and its islands. The general form and colouring of the animal are so similar to that of the Mouse Deer, or Traguli, from Java, Ceylon, and India, that it was natural it should be placed with them in the same genus. But the Earl of Derby having kindly sent a specimen with its skull to the British Museum, the examination of the bones of the head have at once proved, that instead of being a species of an Asiatic genus, it is the type of a peculiar genus as yet only found in Africa, and therefore not, as has hitherto been thought, an exception in the geographic distribution of Mammalia.

The skull is short with short broad nasal bones, which are dilated and rather truncated behind; the intermaxillaries are also short and truncated behind, not extended behind the base of the upper canines. The ear-bones are large, vesicular, and produced beyond the surface of the bones of the skull, while in the genus Moschus the nasal bones are narrow, linear-elongate, and produced nearly to the front edge of the orbit; the intermaxillaries are large, dilated behind, and produced behind between the maxillaries and the front of the nasal bones, and the ear-bones are small and inclosed in the base of the skull : from these characters and the pig-like habit of the animal, I propose to form for it a genus under the name of Hyemoschus. The skull is much more like that of the genus Tragulus than of Moschus, as it agrees with it in the large size and vesicular form of the ear-bones; but the Traguli are easily known from the Hyemoschi by the large size and triangular form of the hinder part of their intermaxillaries, which reach to the nasals and form the front part of the cheek in these animals.

1. Moschus.-Nasal bones linear-elongate; ear-bones small, inclosed; intermaxillaries large, produced behind, narrow, and extended far beyond the base of the upper canines. M. moschiferus, M. leucogaster, $M$. chrysogaster.

2. Tragulus.-Nasal bones elongate, rather dilated and truncated behind; ear-bones large, vesicular; intermaxillaries large, triangular, broad, oblique, truncated behind, hardly produced beyond the base of the upper canines between the maxillaries and the nasal bones. T. javanica, T. Stanleyanus (M. ecaudatus, Temm. MSS.).

3. Hүемовchus. - Nasalbones short, dilated, and truncated behind. Ear-bones large, vesicular; intermaxillaries small, short, scarcely dilated behind on the front of the maxillaries, and not extended beyond the base of the upper canines. H. aquaticus.-J. E. Gray. 


\section{$2 \mathrm{BHL}$ Biodiversity Heritage Library}

1845. "On a fish allied to Lepidosiren annectens." The Annals and magazine of natural history; zoology, botany, and geology 16, 348-350.

https://doi.org/10.1080/037454809496533.

View This Item Online: https://www.biodiversitylibrary.org/item/71834

DOI: https://doi.org/10.1080/037454809496533

Permalink: https://www.biodiversitylibrary.org/partpdf/60381

\section{Holding Institution}

University of Toronto - Gerstein Science Information Centre

\section{Sponsored by}

University of Toronto

\section{Copyright \& Reuse}

Copyright Status: NOT_IN_COPYRIGHT

This document was created from content at the Biodiversity Heritage Library, the world's largest open access digital library for biodiversity literature and archives. Visit BHL at https://www.biodiversitylibrary.org. 